University of Wollongong

Research Online

Faculty of Science - Papers (Archive)

Faculty of Science, Medicine and Health

$1-1-2003$

\title{
Environmental (re)education and local environmental knowledge: statutory ground-based monitoring and pastoral culture in central Australia
}

Nicholas J. Gill

University of Wollongong, ngill@uow.edu.au

Follow this and additional works at: https://ro.uow.edu.au/scipapers

Part of the Life Sciences Commons, Physical Sciences and Mathematics Commons, and the Social and Behavioral Sciences Commons

\section{Recommended Citation}

Gill, Nicholas J.: Environmental (re)education and local environmental knowledge: statutory ground-based monitoring and pastoral culture in central Australia 2003, 85-104.

https://ro.uow.edu.au/scipapers/1024

Research Online is the open access institutional repository for the University of Wollongong. For further information contact the UOW Library: research-pubs@uow.edu.au 


\title{
Environmental (re)education and local environmental knowledge: statutory ground-based monitoring and pastoral culture in central Australia
}

\author{
Abstract \\ Ground-based monitoring of rangeland condition is common in Australian pastoral administration \\ systems. In the Northern Territory, such monitoring is officially seen as a key plank of sustainable pastoral \\ land use. In the NT and elsewhere, these monitoring schemes have sought to increase participation by \\ pastoralists. Involvement of pastoralists in monitoring is theoretically an educative process that will \\ cause pastoralists to more critically examine their management practices. Critical perspectives on the \\ relationship between rangelands science/extension and pastoralist knowledge systems and concerns, \\ however, suggest that pastoralists' reception of such monitoring schemes will be influenced by a range of \\ social contexts, including the character of pastoralist environmental knowledge. Fieldwork with \\ pastoralists in Central Australia shows that the process by which pastoral environmental knowledge \\ develops has rich experiential, historical and social dimensions. These contexts play a role in framing \\ pastoral environmental knowledge and in shaping pastoralists' interpretations of environmental events \\ and information from other parties. Pastoralists will assess information from monitoring in light of these \\ contexts. The nature of the ground-based monitoring scheme is such that the very environmental \\ knowledge that it seeks to reform may in fact be confirmed or otherwise interact with pastoral knowledge \\ in unanticipated ways. Lack of systematic evaluation of the scheme and of pastoral environmental \\ knowledge, however, precludes definitive judgements at this stage. The apparently central role of \\ monitoring in NT pastoral land administration, however, suggests that the assumptions underlying the \\ scheme and its implementation be reassessed.
}

\section{Keywords}

central, culture, monitoring, ground, statutory, knowledge, local, re, pastoral, australia, environmental, education

\section{Disciplines}

Life Sciences | Physical Sciences and Mathematics | Social and Behavioral Sciences

\section{Publication Details}

Gill, N. J. (2003). Environmental (re)education and local environmental knowledge: statutory groundbased monitoring and pastoral culture in central Australia. Rangeland Journal, 25 (1), 85-104. 


\title{
Environmental (Re)education and Local Environmental Knowledge: Statutory ground-based monitoring and pastoral culture in Central Australia
}

\author{
Nicholas Gill \\ School of Geosciences \\ University of Wollongong \\ NSW 2522 \\ Ph. (02) 42214165 \\ Fax. (02) 42214250 \\ Nicholas_gill@uow.edu.au
}




\section{Abstract}

Ground-based monitoring of rangeland condition is common in Australian pastoral administration systems. In the Northern Territory, such monitoring is officially seen as a key plank of sustainable pastoral land use. In the NT and elsewhere, these monitoring schemes have sought to increase participation by pastoralists. Involvement of pastoralists in monitoring is theoretically an educative process that will cause pastoralists to more critically examine their management practices. Critical perspectives on the relationship between rangelands science/extension and pastoralist knowledge systems and concerns, however, suggest that pastoralists' reception of such monitoring schemes will be influenced by a range of social contexts, including the character of pastoralist environmental knowledge. Fieldwork with pastoralists in Central Australia shows that the process by which pastoral environmental knowledge develops has rich experiential, historical and social dimensions. These contexts play a role in framing pastoral environmental knowledge and in shaping pastoralists' interpretations of environmental events and information from other parties. Pastoralists will assess information from monitoring in light of these contexts. The nature of the ground-based monitoring scheme is such that the very environmental knowledge that it seeks to reform may in fact be confirmed or otherwise interact with pastoral knowledge in unanticipated ways. Lack of systematic evaluation of the scheme and of pastoral environmental knowledge, however, precludes definitive judgements at this stage. The apparently central role of monitoring in NT pastoral land administration, however, suggests that the assumptions underlying the scheme and its implementation be reassessed.

Keywords: range condition, monitoring, range policy, participatory management, local knowledge 


\section{Introduction}

In recent decades there has been a shift in Australian land and resource use and management legislation and policy from an emphasis on allocation and 'wise use', towards a concern with environmental protection and ecological sustainability (Grinlinton 1990, Conacher and Conacher 2000). To varying extents, changes in legislation for the use and management of Australia's arid and semi-arid pastoral lands have reflected this shift in their objectives, requirements for land management, and land condition assessment (Ledgar 1994). Monitoring of land condition, either by government scientists, or by pastoral landholders, or by both, is a key means by which Australian state and territory governments hope to facilitate sustainable land management on pastoral land (Burnside and Chamala 1994, Ledgar 1994). This paper is focussed on the scheme adopted by the Northern Territory consequent to the introduction of the Pastoral Land Act, 1992. As required by this legislation, the NT Pastoral Board has developed a monitoring system in which pastoral landholders are to be involved in monitoring vegetation and soil condition at permanent monitoring sites. As discussed below, this monitoring scheme is a key plank upon which the NT government has claimed progress towards implementing a policy framework that will facilitate sustainable pastoral land use (Ledgar 1994).

In theory, ground-based monitoring by landholders, such as occurs in the NT can lead to improved management in two ways. First, it can provide opportunities for self-directed learning by pastoralists, in which the 'data from ground-based sites provides the concrete experience needed to stimulate reflective observation and learning' (Burnside and Chamala 1994, p. 225). Second, in concert with its role in encouraging reflective learning, monitoring can complement and assist 
pastoralist decision-making processes (Burnside and Chamala 1994). As Burnside and Chamala (1994) note, however, in their 1994 review of monitoring by landholders, such schemes are at an 'uncertain' stage - their methods of questionable value in assessing change, and the schemes not yet embraced by landholders. This paper seeks to build on their critical yet optimistic appraisal of monitoring schemes. Based on qualitative and ethnographic research with pastoralists in the Alice Springs pastoral district in 1996 and 1997, it proposes that the official monitoring scheme to be carried out by pastoralists carries the potential to perpetuate and perhaps reinforce the very attitudes and beliefs that the scheme ostensibly seeks to alter. Furthermore, it suggests that pastoral environmental knowledge is born of significant experience and cultural development, and is knowledge that might productively be engaged with, not simply reformed. This proposal will be based upon placing the technology of monitoring in context (Ison 2000a). In this case, the cultural and historical context of the current monitoring scheme. Specifically, this will entail discussion of the history of monitoring in Central Australia (largely to the period of fieldwork), of elements of pastoralist environmental knowledge, of pastoralist perceptions of previous monitoring schemes, and of the associations pastoralists make between this technology, the sustainability of the industry, and past and present ecologically-based critiques of pastoralism. Monitoring may be central to NT pastoral legislation and administration, but, like ‘agricultural information’ as a whole, for many pastoralists it is 'nothing more nor less than a subset of [the] social fabric' of their world of relationships, experiences, knowledge and interactions with both people and nature (Ison 2000a, pp. 123-124). 
While based upon sound qualitative research, in a sense this paper is speculative. In it, I seek to apply some insights into pastoral culture to a significant land management issue that was not the original focus of research. I also seek to consider the NT ground-based monitoring scheme in light of recent thinking about the origins, development, role and status of local environmental knowledge, particularly relative to the role of knowledge derived from formal science, and also about extension in the rangelands. I hope thereby to prompt further critical thinking about monitoring schemes that have pastoralist 'education' as their focus.

An earlier version of this paper attracted comment from the Centralian Land Management Association (CLMA; the pastoralist Landcare group in Central Australia) including criticism that I had not taken account of some recent developments in ground based monitoring in Central Australia. I acknowledge that the CLMA has initiated a pastoralist-driven monitoring scheme (Centre Land Watch - CLW) since this research was undertaken (see Walsh 2002) and I have considered and incorporated certain feedback that I received from the CLMA. The paper remains however, substantially unmodified, for several reasons. First, my understanding of the nature of the CLW initiative is that the arguments in this paper are consistent with the rationale and 'bottom up' approach of the CLW, and in fact provide an argument in favour of such pastoralist-driven schemes. Second, I think my arguments regarding the importance of local environmental knowledge systems in land management have significance both in and beyond the example of Central Australia and may be of interest to both pastoralists and land administrators elsewhere. Third, my characterisation of Central Australian 
pastoral environmental knowledge, while a generalisation from my analysis, is not based solely upon information dating from the 1990s. It derives from a range of sources and periods and illustrates the persistence ${ }^{1}$ of several themes discussed in this paper. My observation of this persistence leads me to three points. First, it does not imply that I see pastoralists as backward and unchanging, but does imply that I see their environmental knowledge as having a strong basis in history and experiential learning and that the ongoing development of this knowledge in an era of Landcare, of ecological thinking, and in light of economic imperatives for more efficient pastoral management is a topic of great relevance for rangelands management. Second, and in light of this long term perspective, my basic question regarding how pastoral environmental knowledge might interact with information from contemporary monitoring schemes remains relevant to the operation of CLW, the origins of which introduce new variables. Finally, I write of those aspects of a framework of pastoral environmental knowledge that I was able to glean from field and historical research that was not primarily focussed on environmental knowledge per se. I see my analysis as a beginning, to be tested, modified, rejected or expanded as others may see fit in light of more focussed research or experience. Indeed, the operation of the CLW scheme in a higher rainfall period such as Central Australia has been enjoying in recent years may well provide a suitable opportunity for such investigation.

\section{The Study}

The fieldwork for the study from which this material arises was conducted in 1996 and 1997 (Gill 2000). I focussed on land and environmental matters, and aimed to investigate the nature and foundations of non-indigenous pastoralists' 
responses to contemporary social change that questions their cultural status, and occupancy and use of land. In particular, I examined pastoralist conceptions of nature and environment, their relationship to land, and the processes by which these relationships developed and are sustained.

The project was undertaken at a stage when rangelands were under considerable scrutiny. It was a period of heightened criticism of rangelands pastoralism from both environmental and Aboriginal perspectives. It was also a time in which there was growing interest from researchers, administrators and funding bodies in social science research in the rangelands (Holmes 1994, Morton and Price 1994). In particular, it was suggested that greater understanding of the 'value orientations' (Holmes 1994, p. 149) of rangelands users was required. Furthermore, it was argued that research was needed that provided for greater potential for dialogue between researchers and rangelands inhabitants, and which did not necessarily seek rigour through method alone, but also through adopting a responsive, self-reflective approach (Ison 1993, Shulman and Penman 1994).

To meet these concerns and to most appropriately address the research aim, I developed the project as an ethnographic ${ }^{2}$ study in one area, the Alice Springs pastoral district, using a variety of qualitative research methods. The benefits of this qualitative case study approach include:

It permits the grounding of observations and concepts about social action and social structures in natural settings studied at close hand. It provides information from a number of sources and over a period of time, thus making a more holistic study of complex social networks and 
of complexes of social action and social meanings. It can furnish the dimensions of time and history to the study of social life, thereby enabling the investigator to examine continuity and change in lifeworld patterns. (Orum et al. 1991, p. 6-7).

During 1996 and 1997 I visited sixteen stations in the Alice Springs pastoral district and I visited seven at least twice. Using a semi-structured interview guide I interviewed thirty-four non-indigenous individuals who were either part of the family who owned the station and were active in running the station, or were managers, working for absentee owners. I also interviewed five retired pastoralists, and pastoral representatives from the Northern Territory Cattleman's Association and the Centralian Land Management Association (CLMA; a pastoral Landcare group). In addition, I travelled around stations with pastoralists, observing and often participating in station work. These occasions provided opportunities to discuss a wide range of issues relevant to the research and to explore matters that arose in interviews.

To enhance the reliability of this research I also used a range of other sources. These included observations at meetings, interviews with past and present government staff, and documentary sources such as newspapers, transcripts of hearings and inquiries, published books, photos, reports, archival material relevant to pastoral land management in Central Australia, and oral histories held by the Northern Territory Archives Service.

In order to make sense of this disparate information I used coding methods to break the information down. This essentially involved an iterative process of 
classifying the information according to categories derived both from the research aims and from the information itself (Patton 1990). For example, the statements, concepts or ideas about land expressed by non-indigenous pastoralists were captured in a range of general categories, including environmental beliefs, stewardship, insider/outsider identity, and attachment to land.

As is frequently the case with qualitative research (Minichiello et al. 1990), such categories evolved over the fieldwork period and subsequent to it. There was no clearly defined point at which fieldwork ended and analysis began. The categories developed in a non-linear fashion as themes and ideas emerged, and were developed or discarded throughout both the fieldwork and analysis stages. Their co-development entailed adjustments and focussing of interviews and information gathering. Such a flexible and reflective approach to data analysis and collection is consistent with the suggestions for rangelands research outlined above. It allows the building of 'thick description', where the various sources of information are used to:

Combine...issues of meaning and symbolic expression with an analysis of the political and economic contexts within which such expressions are manifested [and] to furnish contemporary expressions of meaning with historical lineage, to look back and contextualise the ideas and views of the present in terms of the past (Jacobs 1999, p. 23).

Assessing pastoralists' views on the monitoring system then being established was not a focus of this project. Nonetheless, current and past ground or site- 
based monitoring systems frequently entered discussions and interviews during fieldwork. From pastoralists' observations and comments on the past and present sites and the process of establishing them, and by juxtaposing pastoral understandings of environmental change with the aims of the current groundbased monitoring system, it is possible to contextualise ground-based monitoring in pastoral culture. From this can be gained insights into how the NT groundbased monitoring system is likely to be interpreted by at least some Central Australian pastoralists. Feedback was sought from a key informant and from the CLMA regarding the application of this research to this discussion of the monitoring scheme, and this has assisted in modifying sections of this paper.

\section{Rangelands Monitoring in Australia}

Devising suitable systems of tenure and administration under conditions of low but highly variable biophysical productivity has been a constant challenge for Australian rangelands administrators (Heathcote 1987). Implementing systems to provide information concerning land condition under grazing upon which management and regulatory decisions can be made, and if necessary enforced, has long been a key issue. In Australia, as elsewhere, resource inventories and monitoring systems, have become central to this aspect of rangeland administration (Wilson et al. 1984, Abraham and Stanley 1986, Holm 1986, Burnside and Faithful 1993, Burnside and Chamala 1994, Donovan, 1995). Monitoring is intended to provide information on soil and vegetation trends to both administrators and pastoral landholders. In theory, pastoral landholders are to both receive results from monitoring on their land, and are, ideally, to be involved in the monitoring process themselves once 'administrative agencies' 
have established a 'framework' (Wilson et al. 1984, p. 124). From the perspective of the rangeland administrator or scientist, this process aims to overcome the problem of memory being an 'unreliable guide' to management decisions in the spatially and temporally variable rangelands environments (Harrington et al. 1984, p. 10).

The development of monitoring systems which are not prohibitively expensive and which are able to produce information on range trend in a form that is useful for decision-making by both administrators and pastoralists has been problematic. Environmental variability in space and time in Australian rangelands means that ground-based monitoring at the 'usual scale [can] provide highly variable results both spatially and temporally' (Friedel 1994, p. 16). The problems associated with ground-based monitoring have been summarised by Burnside and Chamala (1994, p. 223):

- Landscape variability resulting in a low representativeness of site data;

- The difficulty of separating grazing impacts from seasonal and site effects;

- The difficulty in extrapolating data from a few points to a whole paddock or grazing area;

- The time required for trends to emerge.

These problems have led rangelands scientists and Northern Territory administrators requiring a sound and cost-effective regulatory tool, to develop and apply range condition assessment methods using remotely sensed data (for 
example see Bastin et al. 1993) in conjunction with ground-based systems operated by pastoralists.

\section{Range Assessment and Monitoring in the Northern Territory}

Monitoring of rangeland condition in the southern NT dates from the 1950s when the Animal Industry Branch botanist, George Chippendale, established transects and exclosures to monitor the impact of grazing (Bastin et al. 1983, interview, George Chippendale, 13/4/1997). Since then a variety of monitoring schemes have been run in the NT (Bastin et al. 1983, Department of Primary Industry and Fisheries 1996).

In 1992, a new scheme was introduced under the NT Pastoral Land Act. In the lead up to the implementation of this act, Max Ortmann, the Minister for Lands and Housing, described it as 'the most significant pastoral land tenure reform in the Territory's history' (Ortmann 1992). While the act also abandoned development covenants and converted many term pastoral leases to perpetual leasehold, the government often emphasised the importance of the monitoring scheme to the new institutional regime. For example, in his second reading speech, the Minister said ‘successful monitoring of the Territory’s pastoral lands is the key to a land care based administrative system' (NT Legislative Assembly Hansard, 19/11/1991, p.3495).

The monitoring scheme is characterised by two 'tiers'. Tier two uses a range of techniques to provide 'objective, scientific information on the condition of pastoral land' (Northern Territory Pastoral Land Board 1996, p. 6). Tier one is 
more directly aimed at involving pastoralists in monitoring the impact of their management practices and of changes and trends in soil and vegetation condition and composition. The objective of tier one is to:

\begin{abstract}
Assist pastoral lessees with management decisions by providing a means of documenting changes at specific pasture sites over time. Lessee involvement is encouraged in both the selection of monitoring sites and the collection of data. The system has been designed to increase lessee awareness of plant and pasture behaviour (Northern Territory Pastoral Land Board 1995, p. 6).
\end{abstract}

Tier one involves establishment of monitoring sites on pastoral leases. Site locations are established by officers of the Department of Lands, Planning and Environment in conjunction with pastoral landholders or managers. The sites, marked by steel pickets, are installed and initially assessed by government staff. Pastoralists are encouraged to revisit the sites every twelve months, rephotograph the site, and record pasture composition and state, extent of bare ground, recent stocking history, rainfall, and seasonal growth response. It is envisaged that government pastoral officers will revisit monitoring sites in central regions every three to five years, and every two years in other regions (Northern Territory Pastoral Land Board 1995). In light of this schedule, the willingness of pastoralists to monitor the average of ten sites on their properties is central to the success of the program. However, in 1995, the board reported that, while pastoralists in Central Australia were accepting of the monitoring scheme, their level of involvement in selecting sites and in ongoing monitoring was ‘disapppointing’ (Northern Territory Pastoral Land Board 1995, p. 7). More 
recent moves by the CLMA to support monitoring (the Centre Land Watch project) driven to a greater extent by pastoralists were in part prompted by such problems (Walsh 2002).

As with tier two, the Pastoral Land Board intends that pastoralist involvement in the ongoing monitoring of vegetation and soils at the sites will improve management by pastoralists through improving their understanding of the relationships between pasture condition and compositions, grazing management, and seasonal response. The Board believes that it will be 'beneficial' for lessees to regularly photograph and assess the sites:

Over time these additional photos will provide a valuable pictorial history of the monitoring sites aiding pastoralists in their understanding of the range condition and the seasonal growth responses at individual monitoring sites (Northern Territory Pastoral Land Board 1995, p. 6).

Extension material concerning the monitoring system also emphasises the role of photography and other information as an aid to memory and as an learning tool, taking the 'guesswork out of remembering how the country used to be' and '[improving] knowledge of plant species and pasture behaviour under grazing and other management practices' ('Monitoring rangeland in the Northern Territory', folder produced by Department of Lands, Housing and Local Government). Such a perspective, in which scientific knowledge is privileged and pastoralists are characterised as lacking the knowledge required for sound land management, has been pervasive in rangelands management and science (Russell and Ison 2000), as it has more generally in agricultural extension and 
land management (Kloppenburg 1991, Murdoch and Clark 1994, Clark and Murdoch 1997). How can we characterise or contextualise pastoral environmental knowledge?

\section{Pastoral Culture and Environmental Knowledge}

The 'good' of Central Australia

Pastoralism has been present in Central Australia since the late nineteenth century. Over this time, pastoralists have experienced great environmental variability and, collectively at least, have survived to the present day. Pastoral environmental knowledge is inseparable from this history of survival and experience, and its development is a social process that continues to this day. The concept of the 'good' of Central Australia can be used to illustrate the entanglement of pastoral environmental knowledge with pastoral culture and identity.

In 1996, at a meeting of pastoralists and others south of Alice Springs, a station owner got to his feet and said 'we know the good of Central Australia'. This statement draws upon the past and the survival and development of pastoralism and its people. It speaks to the present, referring to an environmentally benign and reciprocal relationship between the land and pastoralists. It reaches into the future by suggesting that the 'good' of the land is evident to, and nurturing of, those who have stayed and continue to stay. 
The pastoral sense of the 'good' of Central Australia is potentially important to the topic of monitoring. Pastoralists settled Central Australia, survived to make a home, to experience the variability of the environment, and, in their views, have had their faith in the productivity of the land rewarded with the development of the industry and of pastoral families and communities (Gill 2003). Essentially, the 'good' refers to the reciprocal relations developed between pastoralists and the land in pastoral culture. In pastoral culture, these are relationships of mutual nurturing - the land nurtures them if they have faith in, and nurture, it. Pastoral relationships to land are fundamentally different to those of rangelands scientists and, contrary to the view of critics of pastoralists (for example see Horstmann 1997), consist of far more than the legal relationships embodied in pastoral legislation and leases. Relationships to land are forged in history, through labour, through social and family reproduction, and through events, such as drought and conflict over land. This is, in part, the context of pastoral environmental knowledge. It is knowledge that is not separate from wider cultural systems, beliefs and mythologies that themselves have developed through encounters with nature (Ison 1993, Murdoch and Clark 1994, Gill 1997).

As has been shown clearly elsewhere, failure to address or acknowledge differences between local and scientific knowledge systems directly affects land use and land management, and contributes to generation of conflict over land and environmental management (Gill 1994, Haenn 1999, Williams 2000). In the rangelands of Australia and elsewhere, failure to acknowledge the limits and partiality of knowledge generated through rangeland science has limited the effectiveness of extension and research efforts (Ison 1993, Russell and Ison 
2000). This failure has for example, led to researcher definitions of rangeland 'problems' diverging significantly from pastoralists' definitions in both developing nations (Russell and Ison 2000, Williams 2000), and in Australia and New Zealand ( Dominy 1997, Ison 2000b, Dominy 2001). The approach of the researchers can provoke antagonism towards research that is perceived by pastoralists as not only a waste of resources, but as actually inimical to their interests (Williams 2000). Such attitudes to researchers and government staff have been reported in western NSW rangelands (Digman and Major 2000, Ison 2000b). In this research I found such attitudes common amongst Central Australian pastoralists.

Central Australian pastoral culture has developed within and through environmental variability. In the course of occupying land, pastoralists experience this variability on both a daily basis, over years or lifetimes, and through family and collective memories. On a daily basis, pastoralists travel across their stations, both on tracks and cross-country. The spatial variability is encountered as one moves between different land systems. Vegetation, landforms and soils change constantly over relatively short distances. In the course of this work, pastoralists can gain detailed and intimate knowledge of their land. Over time, pastoralists observe the variations in vegetation, soil and landforms as rains, droughts and floods come and go, endlessly reshaping the land. This process creates pastoral knowledge and histories of land and develops a perspective on landscape that emphasises change. In pastoral culture, these histories are seen as personal; they exist in relation to an individual and their presence on the land, and collectively, because in pastoral culture there is a 
shared sense of this particularity and experience of land over time. Over longer periods this variation enters family and collective memories in the form of both a generalised set of beliefs about landscape processes, and in the form of certain anecdotal stories that gain currency in families and in the pastoral community. Thus does land become country; 'habitat...an inhabited and deeply culturalized landscape’ (Dominy 2001, p. 3).

In pastoral conceptions of country, the distinctions between nature and society are collapsed through lived experience. In particular this occurs through productive and reproductive labour that transforms both the land and people. This is part of the context into which the monitoring systems are inserted. The terms and aims of the monitoring systems are derived from the dualistic knowledge systems of ecological science, a science that is today transnational, and part of global agendas for ecological and resource sustainability. How are its terms and concepts, its divisions and boundaries of nature and land, and its notions of sustainability, vegetation and soils, faring within pastoral culture? How are they being received, evaluated, and (re)interpreted? On what terms are they accepted or rejected?

An evaluation of monitoring schemes along the lines of the questions above, would constitute a project in itself. To begin to consider the answers to some of these questions, I will discuss some aspects of pastoral environmental knowledge and its generation, and consider how the monitoring scheme being implemented might interact with this knowledge. Such a beginning will be useful for future investigation into rangelands monitoring by pastoralists. 


\section{Environmental Change at Historical Time Scales}

Pastoral views on landscape processes and the role of pastoralism and cattle are evident at both geological and historical time scales. This paper will focus on the historical time scale, and will largely consider the period from the 1950s to the present day. The following section will focus on processes, such as vegetation change and erosion. In these sections I will illustrate the environmental and historical basis for pastoralist beliefs about their position and role within the landscape.

In discussions with pastoralists, environmental variability was a significant and recurring theme throughout what they said about the land and themselves. In pastoral culture, the emphasis on variability is not limited to seasonal and annual variations, it also encompasses changes over decades. Certain observations and events lead pastoralists to perceive of a landscape that functions on a grand scale, and in which human activities constitute a marginal element. In addition, pastoralists see their place in this landscape in ways that contrast significantly with the place of non-pastoralists, specifically those identified as their critics. For example, the 1958-65 drought and associated debates over pastoral land use and subsequent changes in the landscape are both important in shaping pastoral responses to criticism today. These examples will be used to explore aspects of pastoral culture and its relationship to land.

Individual and social memories of the 1958-65 drought resonate in pastoral culture today. The 1958-65 drought was an occasion of great criticism of 
pastoralism in Central Australia and older pastoralists look back to this period when addressing criticism of the industry in the 1990s. An article in the December 1966 edition of the Inland Review' entitled 'Who Said the Centre was Dead?' provides some evidence of how pastoralists saw the apparent 'recovery' of Central Australia after the rains in early 1966. The article emphasises that critics of the industry had claimed that the land in the Centre was so damaged that it would not produce pasture again. In contrast there were now 'tens of thousands of square miles of.... colourful canvas where cattle [were] rolling fat' and one 'jubilant' pastoralist was quoted as saying the cattle were 'just eating their bloody heads off' (Anon. 1966, p. 26).

Tony Greatorex, former manager of Palmer Valley station and Secretary of the Centralian Pastoralists' Association (CPA), wrote on behalf of pastoralists. He argued that once the rains came, 'the country made its usual and expected recovery' (Anon. 1966, p. 27). Of the critics of the pastoral industry he wrote 'few...have been in the country long enough to appreciate' this resilience of the land (Anon. 1966, p. 27).

These views were paralleled in pastoralists' verbal submissions to the NT Land Board's 1964 inquiry into the drought ${ }^{4}$. This inquiry provides clear information as to pastoralists' beliefs about land that continue to resonate today and to inform their sense of a place on the land and their rights to occupy it. For example, William Brown of Annitowa told the Land Board: 
After the 1928 drought it rained in 1929, in March 1929 it rained and from then on they were getting fat cattle off here. After they stocked up I came down here and they were stocking up then and right up to 1956 the seasons were fair to good and the herds increased... and now it has gone back again. It's a cycle, in my opinion, it's a cycle that comes every 25 to 30 years (William Brown, evidence to NT Land Board July 1964).

Not only is the country resilient and able to recover from severe dry periods and produce fat cattle, but, as Brown implies, and as other pastoralists state, long term residence in Central Australia and close experience of the land is required to develop knowledge of its ‘true’ nature and resilience.

In addition, evidence of pastoralists to the Land Board in 1964 invokes a feeling of faith in the land. Collectively, they argued that they see an inherent productivity, a sometimes hidden potential, seen only by virtue of experience of decline and recovery. At the time, Greatorex spelt out this faith in the land in a call for critics to assist in restoring faith in the land and in the pastoralists:

After all, the pastoralists have toiled to get a living out of the country and not one of them walked off even when the experts were claiming that the Centre was finished, the pastoralists' position hopeless, and advocating the closing down and de-stocking of the whole of the Northern Territory south of Alice Springs. They had sufficient faith to struggle on because they and their wives believe in the country and its ability to recover (Anon. 1966, p. 27). 
This experience of the country in all its variation is a key moment in shaping pastoralist beliefs about land. For pastoralists, this experience rewards faith in the productivity of the land. This cycle of faith and reward sets up reciprocal relationships between pastoralist and land. Amongst pastoralists, such relationships serve to distinguish them from others who do not have this experience of the land.

The rains of 1966 and subsequent high rainfalls from 1973-1978 (Griffin and Friedel 1985) brought changes in the vegetation that, in pastoralists' perspectives, vindicated their faith in the land. In their view the country 'came back'. This refers to a belief in the resilience of country and its ability to once more produce 'feed' even after an extended dry period or heavy stocking. Speaking of the recovery after the rains in 1966 Rose Chalmers said of the country:

But you don't know, you get the right rain and there it all is! Even that beautiful button grass which is the best grass of all. And that was [sic] just miles of it (interview 16/11/96).

In this view, the country is reborn over and over again, it just needs the right combination of rainfall and timing to realise its inherent potential.

The growth of trees and shrubs after a period such as 1958-65 is taken as evidence of the resilience and productivity of the country. In pastoralists' views, if the country was as damaged as their critics claimed, then such growth would 
not be possible and the pastoral industry would be finished. This is the view that underlies contemporary responses to critics. The late Ted Hayes, as someone who had 'spent his whole life in the Alice Springs district and [had] seen vast changes' took this up in a posthumously published letter that has become a reference point for pastoralists:

We were led to believe following the drought of the 1960s that if the country ever recovered it would take at least 10 years to do so. The agronomist of the period was proved to be very wrong in his assessment and, like many scientists and experts quietly left the district. In 20 years time the present degradation theory will be proved as wrong and the people making all these statements will have long left the Northern Territory...If only they knew the history of the area: the industry has been in existence here for over 100 years (Centralian Advocate, 25/3/88).

Hayes' recollections of past critics and his comparison of them to present day conservationist critics was paralleled by comments in 1996 and 1997 by other pastoralists. For example, 'Boof' Smith of New Crown station also expressed the idea that tree and shrub growth represents an improvement in the country. In a letter to the Centralian Advocate, an Alice Springs conservationist had made allegations of overgrazing in the area of New Crown where 'kilometre after kilometre of dead stumps [attested] the enormous impact overgrazing has had on what were once productive mulga woodlands' (Centralian Advocate, 31/5/96). Smith responded defensively: 
The dead stumps have been there since at least the early thirties, as attested to by my father who travelled through that region extensively. And if examined closely enough it is evident that they died as a result of bushfires... There are more trees in the country now than in the forties, and we have the photos to prove it (Centralian Advocate, 4/6/96).

In the above views, the current 'generation of experts' are comparable to those of the 1960s, and Smith wonders if they will be around when 'the rains fall again as they must, and the country is once again in good heart' (Centralian Advocate, 4/6/96). In pastoralists' views, this cycle of renewal and destruction in a variable landscape and the presence of dead trees in any given place, is of little fixed meaning independent of certain historical events and processes, the knowledge of which they claim.

In summary, pastoralists see that the industry has survived extended dry periods previously and has done so in spite of periodic bouts of criticism about land degradation and long-term natural resource depletion. Industry survival is taken to demonstrate two things to pastoralists. First, it shows the 'normality' of climatic fluctuations and cycles, and that these fluctuations pose no threat to the pastoral industry. Second, given the industry has survived stressful periods, sometimes in spite of scientific and conservationist criticism, pastoralists have not seen the demise of their industry. On the contrary, they have seen what they believe to be tremendous recovery from dire situations. In other words, from the pastoralists' point of view there has been little vindication of the criticism levelled at them at various times. In their view, the country has continually renewed itself and shown that it can support the presence of pastoralism. There is 
relatively little room for land degradation in these geological and historical perspectives on landscape. Land degradation potentially implies linearity or a downward but fluctuating trend in the landscape. Amidst a largely linear and predestined view of pastoral settlement, pastoralists see cycles of landscape destruction and renewal over decades and over geological epochs. These cycles dwarf their presence and that of their cattle. In these historical and geological perspectives of landscape, the pastoral industry and their cattle exist within natural cycles and the presence of pastoralism is thus naturalised.

\section{Living with Chaos and Gardening the Centre}

Pastoralists also naturalise cattle at shorter time scales and at smaller spatial scales. At these scales cattle not only exist within natural processes but they also enhance them, 'improving' the landscape in ways that pastoralists see as 'natural'.

In a landscape largely influenced by episodic rainfall events, observable erosion events from scales of metres to kilometres are not uncommon. In their work across stations pastoralists see these changes. Such changes range from soil deposition over a few metres, to large changes in river or creek morphology. Pastoralists often pointed out small movements of soil. They made comments to the effect that erosion has been present since before Europeans arrived and that erosion happens all the time. Debates over 'scalds', or 'scour' zones in Central Australia have reinforced pastoralist ideas about erosion being natural. In the recent past, conservationists have taken such landforms as evidence of soil erosion due to cattle grazing. However, geomorphological research on erosion 
and floods in Central Australia has shown that these features can have origins independent of cattle grazing. Such zones are production/source zones for sediment transfer and may appear in a variety of forms. These range from largely intact areas shedding topsoil to substantially eroded areas comprising bare subsoil. These eroded areas range from small areas to sections of eroded floodplain several kilometres in length resulting from large and rare flood events (Pickup 1985, 1988, Bourke and Pickup 1999).

The work cited above and that of the NT government, which identified stable scour zones on aerial photography dating back to the 1940s (D. Torlach, pers. comm 1/12/94), has strengthened pastoralists' beliefs that erosion is a natural process that occurs independently of cattle grazing. In particular, the identification of scours dating back to the 1940s is consistent with pastoral memories that such scours were always present, including, according to memory, in areas before they were grazed.

As outlined above, vegetation variability over relatively short periods such as season to season, and over small areas, is also a feature of the Central Australian landscape. Pastoralist observations of vegetation change, as in the case of small movements of soil, in the course of their work and travelling around the stations, create a sense of known or intimate landscapes. Intimacy comes from close observation of the state of pastures, from observing groups of young trees and shrubs appearing and slowly growing, from observing the changes in vegetation on any given area or site, or from taking a favoured route home at sunset to see dune country at its sunset-reddened best. This travel provides regular 
opportunities to see large areas of stations under a wide range of conditions. It engenders a view amongst pastoralists that they know the country better than anyone else. As one pastoralist told me, he has seen the country in 'all its moods' and thus knows it better than anyone. As we drove around his station, this pastoralist made it clear to me that varying vegetation cover represents one of the 'moods' of the country.

In the variability of vegetation, pastoralists largely see chaos. Vegetation is seen to change abruptly and often without apparent cause. For example, groups of young trees were pointed out as having arisen from a particular period of rainfall on the area of country in question. More commonly, pastoralists would point out areas or sites clothed in vegetation and would make comments as to their recent vegetation history. Such sites included ones that had been bare of vegetation as long as they could remember, and which had recently and unexpectedly gained vegetation. Other examples included sites where the composition of vegetation was seen to be unpredictable, varying from season to season and between ‘desirable’ and 'less desirable’ pasture species.

In pastoralists' views, their observations of the consequences of cattle grazing can confirm landscape unpredictability. Generally, pastoralists speak of country without cattle as being 'worse' or in the 'same' condition as country with cattle. In dry periods unstocked country is seen to become as bare as country that is stocked. Robert Waudby of Central Mt Wedge station stated these views in 1994: 
We have got to be careful when we talk of land degradation because I can lock up a paddock... and not have animals in there for four years and I can tell you there is not a blade of grass in that area. The white ants have got it, it is lignified ${ }^{5}$, it is blown away (evidence to Senate Standing Committee on Rural and Regional Affairs 15 August 1994, p. 1473).

In this view cattle tread lightly on the land, but again there is apparently chaotic variation and a range of other environmental factors that override the consequences of the presence or absence of cattle.

While pastoralists see the precise nature of change as unpredictable, change as a principle of life in Central Australia is taken as given by pastoralists. The principle of environmental change is fundamental to Central Australia pastoral culture. Pastoralists see that their time, presence and embodied experience on the land, individually and collectively, give them a unique perspective on change. Experiencing change and accepting it, is a key marker in pastoral culture. This appreciation of change is what pastoralists see their critics as lacking. Where some non-pastoralists, for example some scientists with a long history of work in the region, are granted a level of respect from pastoralists, it is often because they have demonstrated to pastoralists an appreciation of change and variability.

Although pastoralists claim to know the country better than anyone, there are limits to the knowledge they claim. For pastoralists, these limits do not act to erode the authority of pastoral knowledge in relation to others, they act to strengthen them. In the face of variability and the inevitability of change, 
pastoralists will often say they do not understand a lot of what they see around them. They also say you need to be in one spot for a long time to begin to gain insight into what the country is doing, to even begin to appreciate the dynamic nature of the landscape. Sometimes this view was expressed in terms of individual lifetimes. One pastoralist in his early thirties often camps out on his station in order to observe and experience the country instead of returning daily to the homestead. He said he has seen a range of short to medium-term cycles in his lifetime, is still learning, and does not see his thirty years as sufficient to grasp what is happening in the landscape. On other occasions this view was put in terms of the Central Australian pastoral industry. One older pastoralist said to me 'who can say if you are doing the right thing, the country's too young to know'.

The view that cattle are, at worst, neutral in their impact on country, is paralleled by a view of cattle as gardeners. This is what is meant when pastoralists say cattle 'are good for country', or cattle 'improve country'. It was a view widely asserted by pastoralists during fieldwork, including some who are adopting 'sound' and 'progressive' management practices, and those who are not. This view was expressed to me by pastoralists, as both a general statement, and with reference to certain types of country. It was generally qualified with reference to the need to not overstock.

Cattle are held to improve country by tilling or turning over the soil, manuring it, breaking up hard surfaces, providing hoof marks for seed and water, and facilitating seed and moisture penetration of the soil. Pastoralists make reference 
to observations of seeds and seedlings in hoof prints, revegetation on bare areas following stocking, and cattle 'opening up' scrub and allowing the sun in. One pastoralist said 'a lot of country in Central Australia is no good until its stocked...its just like ploughing the land'. Another said the 'country likes to be eaten out', 'rank' grass needs to be removed. Such views were found across age groups, from pastoralists in their early twenties to those in their sixties. A teleology ${ }^{6}$ of developing an 'improved' landscape of home from the Wilderness appears to remain in place among pastoralists.

Apart from the instances listed above, one of the main bodies of contemporary evidence for informing this view amongst pastoralists lies in the grazing exclosures (i.e. cattle are excluded from the site) set up by various government and research bodies between 1965 and 1989. There are twelve of these exclosures on nine stations and they were originally set up for a variety of purposes. In the 1990s, the Department of Primary Industries (DPIF) has brought them together as one project. Pastoralists refer to these sites, noting that vegetation outside the exclosure can be 'better' than, or at least the 'same' as, the vegetation inside the exclosure. Such a view did not necessarily come only from pastoralists who had exclosures on their stations. These observations appeared to circulate within the pastoralist community. Moreover, twice in 1997, Bob Lee, the Director of the Northern Territory Cattleman's Association, drew on DPIF results from these sites, to argue in letters to the Centralian Advocate (3/2/97 and 14/10/97), that cattle may be beneficial to native flora: 
The available scientific evidence....is indicating that cattle grazing in Central Australia may be beneficial to the growth of native flora, although it is still too early to draw definite conclusions (Centralian Advocate, 14/10/97).

Results from one exclosure, Spinifex Bore on Mt Riddock station, indicated an 'improvement' in vegetation in that there was a greater increase in two moderately palatable perennial grasses inside the exclosure relative to outside. Overall, however, results from the exclosures were generally 'inconsistent' and it was difficult to make conclusive statements as to the effect of grazing on pasture yield and composition (DPIF unpublished data 1997 and 1999, A. White, DPIF, pers. comm. 15/10/97).

Pastoralists' observations and circulating anecdotes as to the variation across these sites, in concert with this 'scientific' information, concur with pastoral beliefs about variability in the landscape and the place of pastoralism within it. The instances where country is more vegetated or in better condition from a pastoral perspective outside the exclosures, demonstrate to pastoralists that cattle can be 'good for country'.

This belief is not, however, simply an outcome of their observation of the enclosures and of other areas on their stations. The belief that cattle 'improve' the land implies that cattle change the landscape for the better, and, further, they actually play a role in creating it. By ploughing the soil, pastoralists see a role for cattle in realising and enhancing the productive potential of the landscape. In Central Australia, pastoralists see the pastoral presence not only in social 
networks, homesteads, bores and fences, but also everywhere written on the face of the land itself.

That this belief system is not simply related to contemporary observation is also borne out by considering the persistence of the idea of cattle as gardeners. Such views are found in the transcripts of the 1964 Land Board Hearing, and reproduced within families and in published forms such as the late Ted Hayes' views (Anon. 1987), and in Robinson’s (1999) family history that includes her family's early observations of pastoralism and environmental change in the 1920s. In some respects the characterisation of this idea as simply a 'belief' is to trivialise it and risks also misunderstanding pastoral knowledge systems and their roots in colonial and modern ideas and landscapes of 'productivity' and 'improvement'. The transformation of country by cattle is better understood as an integral part of a pastoral culture with historical origins and a significant level of persistence. This persistence occurs despite and because of environmental variability and government pasture research and extension interventions. Pastoral knowledge systems are able to accommodate and incorporate the results of these activities without necessarily being fundamentally challenged, although this does necessarily mean that their management practices will remain unchanged.

Paradoxically, the pastoral narrative of country, change, renewal and creation has gained in strength, or has at least demonstrated its resilience, as a result of the critiques arising from ecological science and the conservation movement. By acknowledging the limits of their knowledge, and by integrating 'scientific' knowledge, such as that from exclosures, with their own observations and 
experiences, pastoralists' accommodate environmental concerns within their conception of stewardship. They are able to absorb environmental and land management concerns and information from scientists and conservationists alike into their systems of knowledge about Central Australian landscapes. They do this in a manner that is entirely consistent with their sense of history, pastoral settlement and views about 'productive' land use. Pastoral culture, as with such rural cultures elsewhere facing external pressures, is able to:

reach into their cultural and symbolic reserves to create and assert an updated sense of distinctiveness, of difference from the other side. They contrive new meanings for apparently old forms. They use the very symbolic devices in virtue of which they imagine themselves to be regarded as anachronistic, parochial, and peripheral; and, by their use, neutralise these perceived implications...the capacity to so respond revitalises the boundary as perceived from inside and thereby signals the renewal of the community (Cohen 1985).

The 'good' allows pastoral narratives of country to be rewritten as a story not only of settlement, but stewardship through settlement, and, today, stewardship through continued pastoral land use.

The concept of the 'good' of Central Australia, or more precisely, the communal and individual experiences, histories, and knowledges of country, which it embodies, provides a framework within which the current monitoring scheme will be interpreted by many pastoralists. The preceding discussion illustrates the complexity of pastoral experiential knowledge and its generation over varying 
temporal and spatial scales. Government monitoring schemes and the 'scientific' information they yield have been and will continue to be one part of pastoralists' experiences. The manner in which current and future monitoring efforts by both the government and the CLMA interact with existing pastoral knowledge and modes of learning is important for the future of participatory rangelands monitoring schemes.

\section{Implications for Monitoring}

The preceding discussion generalises from fieldwork results. Undoubtedly, there were some pastoralists who found the past and present monitoring schemes useful to varying degrees. However, such views of monitoring were not necessarily exclusive of adherence to the culture and views outlined above. This points to further complexity and variation in pastoral belief and knowledge systems that are yet to be examined. Nonetheless, the findings from this research raise a number of questions regarding the tier one monitoring scheme in the NT. As the section on monitoring in the NT outlined, the background to the Tier One scheme implies that there are official concerns regarding pastoral land management, that the scheme will facilitate communication between extension staff and pastoralists, that it will educate pastoralists, and that monitoring is important to the ongoing health of the pastoral industry. From this background it is possible to identify at least the following assumptions contained within the monitoring scheme:

1) That pastoralists perceive and understand the problem that monitoring aims to address. 
2) That monitoring produces information that has the same meaning to pastoralists as to government extension staff.

3) That pastoralists' environmental knowledge is deficient and information is required to overcome this.

4) That monitoring addresses pastoralists' main concerns about maintaining productivity and profitability.

The above discussion, which outlines aspects of the 'social fabric' of pastoralists' worlds, of which monitoring is 'nothing more nor less than a subset' (Ison 2000a, pp. 123-124), raises questions as to the extent to which the first three assumptions hold. The fourth assumption cannot readily be addressed from the available information, nonetheless as an issue that should be addressed, it arises more generally from this discussion. If monitoring is not addressing pastoralists' main concerns in these areas, it is more likely to seen as of relatively little use.

Historically, defining the 'rangeland' problem has been a key point of divergence between rangelands scientists and administrators on one hand, and rangelands users on the other (Russell and Ison 2000). At one level, the NT monitoring scheme seeks to address a perceived problem of pastoral knowledge and management decision-making. This will be addressed with assumption three. More generally, the monitoring scheme addresses the issue of sustainability in the pastoral industry. As discussed above the monitoring scheme has been seen in official circles as central to sustainable pastoral land use. This is reiterated in the NT government’s 1994 'Conservation Strategy for the Northern Territory’, where the pastoral monitoring scheme is part of a broader framework of policies 
and programs promoting ecologically sustainable development in the NT. But what is sustainability in the pastoral context? In past rangelands research, use of the term has been criticised for presuming that the meaning of sustainability is self-evident (Shulman and Penman 1994). In contrast, sustainability is an ambiguous and contested term capable of embodying diverse meanings that may, or may not, overlap (Gale and Cordoy 1994). It only holds clear prima facie meaning within defined contexts where its use is governed by mutually shared norms or where negotiation over its meaning has occurred. Such contexts may include a scientific research community, institutions, or sub-groups such as pastoralists. Frequent comments from pastoralists as to their perplexity over the use and meaning of the concept of sustainability indicated that there has been inadequate dialogue over its application and meaning in the pastoral context.

The notion of sustainability embodied in the monitoring scheme is primarily one derived from its roots in ecological and agricultural science. It is cast in terms of nature as object; as soil, as pasture species, as vegetation resources, and as characteristics capable of being quantified, inventoried, and stored. Such data becomes the building blocks of knowledge that is to be used to achieve sustainable land use. This can be contrasted with the historically-based and experiential knowledge systems of pastoralists which, through the development and survival of the industry and of the pastoral community, becomes itself evidence of sustainability, as well as knowledge for sustainability. Pastoralists are certainly mindful of resources, and share with the NT government a desire for sustainable production. However, as Dominy (2001) has also concluded for NZ high country pastoralists, sustainability for Central Australian pastoralists is not 
so much about the application of technical knowledge and data to land use. Rather, in these rural cultures, it is better characterised as the outcome of processes that create and sustain links and relationships between people within a community and between those communities and the land (Dominy 2001). As described above, over the twentieth century, pastoralists in Central Australia have seen evidence of this form of sustainability as they have seen their country continue to sustain them. Thus for pastoralists, the need for mechanisms to bring about sustainable land use is absent to a significant degree.

The second assumption rests on the idea that environmental data and information regarding attributes such as soil and vegetation characteristics have a pre-given meaning to all parties. The above discussion provides evidence that is not necessarily the case. Pastoral environmental knowledge exists, and is part of, a wider pastoral culture in which nature as object(s) is of less significance than the mutually constitutive relationships between pastoral society and nature described above (see also Gill 2003). Information from the monitoring scheme will be interpreted in light of pastoral memory, communal and individual experiences of environmental change, past encounters with what they see as a passing parade of experts, critics, and other outsiders, and their sense of persistence in country. It will also be interpreted in light of pastoral notions of environmental change described above. These understandings of change may well be significant given that the tier one monitoring sites will no doubt illustrate significant variations in attributes such as vegetation condition and composition. As I outline above, pastoral environmental knowledge can potentially accommodate this in ways that act to confirm and even strengthen their views on the role of cattle in the 
landscape. Moreover, given the methodological flaws of such sites in rangelands environments (Burnside and Chamala 1994, Friedel 1994), it is possible that the photographic and site assessment information generated will be entirely consistent with pastoralist interpretations of change, and not defendable on scientific grounds by extension staff on their rare visits. The legitimacy and educative role of the tier one site information granted by its official status and with its apparent (to the pastoralists) origins in rangelands science, in conjunction with the nature of the information that may be produced, make such a scheme a risky undertaking for government agencies in the context of pastoral culture.

Moreover, the distinction between the nature of the tier one sites and that of the more rigorously designed tier two scheme may not be made by pastoralists. Given the history of such projects in the NT, pastoralists may well see the monitoring effort as simply the most recent of such projects by the government and extension staff and discount it accordingly.

The third assumption characterising farmer knowledge as deficient or lacking, and requiring correction, has also been common in rangelands and other agricultural science and extension (Murdoch and Clark 1994, Russell and Ison 2000). My previous discussion shows that pastoralists in fact can have quite detailed environmental knowledge of their land. This knowledge exists within, and is shaped by, the wide context of pastoral history and experience. This research did not go into the detail of this knowledge. Instead, it has provided a basis for outlining some structural or systemic characteristics of pastoral environmental knowledge. Research in Australian grasslands (Millar et al. 1997) and New Zealand high country (Bosch et al. 1996) has shown that farmers and 
pastoralists can have detailed knowledge and observations of plant species, and that this experience can be integrated into the development of monitoring schemes to maximise their usefulness and uptake. NT Pastoral Land Board reports do not describe in detail how the tier one monitoring system was developed. However, Board annual reports indicate that development was largely conducted within government agencies, with subsequent 'consultation' with the industry via attendance at NT Cattlemen's Association meetings, media interviews, and articles in the 'Pastoral News' newsletter. The result is a tier one monitoring system that closely conforms to methods widely in use in past and present ecological and agricultural science in the rangelands.

This approach to developing the monitoring system is akin to the dominant 'firstorder' tradition of rangelands research and extension described by Russell and Ison (2000), who argue that as a stand-alone approach to rangelands research and extension, it has failed and will likely not achieve its goals. Characteristics of this approach include expert definition of the 'problem', expert identification of solutions, and intervention into social systems that are assumed to be selfcontained and thus amenable to modification through appropriate generation and/or application of the required type of knowledge (Russell and Ison 2000). They contrast this to a 'second-order' approach which is characterised by recognition of the existence and importance of experiential worlds of both the researcher and the farmers, and by cooperation between researchers and farmers in framing, developing and conducting research. It also encompassed the view that rangelands do not exist simply as objectively knowable collections of land systems, plants and soils, but are known through the outcome of social processes 
such as research, running a station, or the interaction of pastoralists and researchers. In western NSW, Russell and Ison (2000) observed that where research adopted a second-order approach, engaged with pastoralists' concerns, and was developed with them, it led to action and enthusiasm among pastoralists (see also Bosch et al. 1996). While it is true that pastoralists are officially seen as 'participants' in the NT monitoring scheme, they are participants within a externally derived framework which produces a particular type of knowledge about rangelands and which is not necessarily compatible with their own epistemology. This begs the question of what approaches to improving land management might have developed had government agencies developed the scheme through dialogue and action research with pastoralists as partners to identify problems and issues. I found many pastoralists interested in improving their land management. But would pastoralists have identified a monitoring scheme such as the tier one scheme in the NT as the way to assist themselves to achieve this? If there was to be a monitoring scheme undertaken by pastoralists, what would a monitoring system designed by pastoralists look like? How would it conceptually and operationally compare to the system in place in the NT? Evaluation of the CLMA Centre Land Watch program would likely offer some valuable insights to these issues and may hold lessons for monitoring schemes elsewhere in Australia and the NT.

\section{Conclusion}

In this paper I have drawn on perspectives and research that emphasise the contextual development of environmental knowledge and the relationship between environmental knowledge and cultures of which it is a part. I have 
sought to use this research to raise some issues regarding the design of the tier one monitoring scheme in the NT, especially regarding its potential relationship with those aspects of pastoralist environmental knowledge that I have outlined here. In particular, I have suggested that pastoral environmental knowledge has been marginalised in the development of the monitoring scheme and could play a greater role than the current scheme allows. This is not to suggest that pastoralist environmental knowledge should necessarily supplant scientific approaches to monitoring; local knowledge is not always sustainable knowledge, particularly as social and economic circumstances change (Murdoch and Clark 1994).

Given the apparent importance of this scheme in NT pastoral administration it is important that its operation and assumptions be subject to scrutiny. This exploratory assessment indicates that the likelihood of the tier one scheme achieving its goals generally among Central Australian pastoralists can be questioned. The scheme should be evaluated on both quantitative and qualitative grounds. In particular, there is great scope for investigations into pastoralists' environmental knowledge and its relationship to knowledge produced by rangelands science and monitoring schemes. Not only does the tier one scheme appear to be based in a way of knowing land that is divergent from the environmental knowledge of country held by many pastoralists interviewed, but also its structure and historical context may lead to the information produced confirming existing beliefs and mythologies amongst pastoralists or taking them in otherwise unanticipated directions. The strength of these broader mythological frameworks of settlement, history, country, and views as to the place of cattle in the landscape go some way to explaining the persistence of beliefs about country 
'coming back' and cattle being 'good for country', that can frustrate scientists and extension staff who may not fully appreciate the origins and complexities of these ideas. The limited participatory approach of the tier one scheme may not be sufficient to allow the development of the sorts of dialogues between pastoralists and extension staff that are required to bring about improvements in pastoral land management. In particular, it runs the risk of not productively tapping into and flexibly engaging with both the structure and content of pastoralists' environmental knowledge.

\section{Acknowledgements}

The fieldwork was undertaken while a PhD student at the School of Geography and Oceanography, University of NSW, Australian Defence Force Academy under the supervision of Kay Anderson and Richard Baker. Land and Water Australia supported the research with a postgraduate scholarship. Thanks to Lesley Head and two anonymous referees for comments. Comments were also received from members of the Central Australian pastoral community. Final responsibility for the content, of course, remains with the author. 


\section{References}

Abraham, N.A. and Stanley, R.J. (1986). Assessment of range condition and trend in the rangelands of western NSW. In: 'Rangelands: A resource under siege' (Eds P.J. Joss, P.W. Lynch and O.B. Williams) pp. 526-7. Australian Academy of Science, Canberra.

Anon. (1966). Who said the centre was dead? Inland Review 1: 17-27.

Anon. (1987). At home on the range: The experience of an NT cattleman. In NT Rural News pp. 25-7.

Bastin, G.N., Hyde, K.W. and Foran, B.D. (1983). Range assessment. In: 'Man in the centre' (Ed G. Crook) pp. 150-66. CSIRO, Melbourne.

Bastin, G.N., Pickup, G., Chewings, V.H. and Pearce, G. (1993). Land degradation assessment in central Australia using a grazing gradient method. Rangeland Journal 15: 190-216.

Bosch, O.J.H., Allen, W.J., Williams, J.M. and Ensor, A.H. (1996). An integrated approach for maximising local and scientific knowledge for land management decision-making in the New Zealand high country. Rangeland Journal 18: 23-32.

Bourke, M.C. and Pickup, G. (1999). Fluvial form variability in central Australia. In: 'Varieties of fluvial form' (Eds A.J. Miller and A. Gupta) pp. 249-71. John Wiley, New York.

Burnside, D.G. and Chamala, S. (1994). Ground-based monitoring: A process of learning by doing. Rangeland Journal 16: 221-37.

Burnside, D.G. and Faithfull, E. (1993). Judging range trend: Interpretation of rangeland monitoring data drawn from sites in the Western Australian shrublands. Rangeland Journal 15: 247-69. 
Clark, J. and Murdoch, J. (1997). Local knowledge and the precarious extension of scientific networks: A reflection on three case studies. Sociologia Ruralis 37: 38-60.

Cohen, A.P. (1985). Symbolism and social change: Matters of life and death in Whalsay, Shetland. Man 20: 307-24.

Conacher, A. and Conacher, J. (2000). 'Environmental planning and management in Australia'. Oxford University Press, Melbourne.

Department of Primary Industry and Fisheries (1996). Technical annual report 1995-1996. Technical Bulletin 250. Department of Primary Industry and Fisheries, Darwin.

Digman, D. and Major, P. (2000). The graziers' story. In: 'Agricultural extension and rural development: Breaking our of traditions' (Eds R. Ison and D. Russell) pp. 189-204. Cambridge University Press, Cambridge.

Dominy, M.D. (1997). The alpine landscape in Australia: Mythologies of ecology and nation. In: 'Knowing your place: Rural identity and cultural hierarchy' (Eds B. Ching and G.W. Creed) pp. 237-65. Routledge, New York.

Dominy, M. (2001). 'Calling the station home: Place and identity in New Zealand's high country'. Rowman and Littlefield, Lanham.

Donovan, P. (1995). 'In the interest of the country': A history of the pastoral board of South Australia 1893-1993. Deparment of Environment and Natural Resources, Adelaide.

Friedel, M.H. (1994). How spatial and temporal scale affect the perception of change in rangelands. Rangeland Journal 16: 16-25. 
Gale, R.P. and Cordoy, S.M. (1994). Making sense of sustainability: Nine answers to what should be sustained? Rural Sociology 59: 311-32.

Gill, N. (1997). The contested domain of pastoralism: Landscape, work and outsiders in central Australia. In: 'Tracking knowledge in north Australian landscapes: Studies in indigenous and settler knowledge systems' (Eds D.B. Rose and A. Clarke) pp. 50-67. North Australian Research Unit, Darwin.

Gill, N. (2003). Transcending nostalgia: Pastoralist memory and staking a claim in the land. In: 'Dislocating the frontier' (Eds R. Davis and D.B. Rose). (in press) Aboriginal Studies Press, Canberra.

Gill, N.J. (1994). The cultural politics of resource management: The case of bushfires in a conservation reserve. Australian Geographical Studies 32: 224-40.

Gill, N.J. (2000). Outback or at home? Environment, social change and pastoralism in central Australia. PhD Thesis, School of Geography and Oceanography, University of NSW, Canberra.

Griffin, G.F. and Friedel, M.H. (1985). Discontinuous change in central Australia: Some implications of major ecological events for land management. Journal of Arid Environments 9: 63-80.

Grinlinton, D. (1990). The "environmental era" and the emergence of "environmental law" in Australia - a survey of environmental legislation and litigation 1967-1987. Environment and Planning Law Journal 7: 74105. 
Haenn, N. (1999). The power of environmental knowledge: Ethnoecology and environmental conflicts in Mexican conservation. Human Ecology 27: 477-91.

Harrington, G.N., Wilson, A.D. and Young, M.D. (1984). Management of rangeland ecosystems. In: 'Management of Australia's rangelands' (Eds G.N. Harrington, A.D. Wilson and M.D. Young) pp. 3-13. CSIRO, Melbourne.

Heathcote, R.L. (1987). Pastoral Australia. In: 'Australia, a geography - space and society' (Ed D.N. Jeans) pp. 259-300. Sydney University Press, Sydney.

Holm, A.M. (1986). The assessment of range trend in Western Australian pastoral shrublands. In: 'Rangelands: A resource under siege' (Eds P.J. Joss, P.W. Lynch and O.B. WIlliams) p. 529. Australian Academy of Science, Canberra.

Holmes, J.H. (1994). Foreword - changing values, goals, needs and expectations of rangelands users. Rangeland Journal 16: 147-54.

Horstmann, M. (1997). The dead heart of the wik backlash. Habitat Australia 25: $34-5$.

Ison, R. (2000a). Experience, tradition and service: Institutionalised R \& D in the rangelands. In: 'Agricultural extension and rural development: Breaking out of traditions' (Eds R. Ison and D. Russell) pp. 103-32. Cambridge University Press, Cambridge.

Ison, R. (2000b). Technology: Transforming grazier experience. In: 'Agricultural extension and rural development: Breaking our of traditions' (Eds R. Ison and D. Russell) pp. 52-75. Cambridge University Press, Cambridge. 
Ison, R.L. (1993). Changing community attitudes. Rangeland Journal 15: 15466.

Jacobs, J. (1999). The labour of cultural geography. In: 'Australian cultural geographies' (Ed E. Stratford) pp. 11-24. Oxford University Press., Melbourne.

Kloppenburg, J. (1991). Social theory and the de/reconstruction of agricultural science: Local knowledge for an alternative agriculture. Rural Sociology 56: 519-48.

Ledgar, R. (1994). A review of land management legislation relevant to Australia's rangelands. In: 'R \& D for sustainable use and management of Australia's rangelands' (Eds S.R. Morton and P. Price) pp. 45-86. Land and Water Resources Research and Development Corporation, Canberra.

Millar, J., Curtis, A. and De Lacy, T. (1997). Perennial grasses in Australia: The place for local knowledge. Rangelands 19(2): 6-11.

Minichiello, V., Aroni, R., Timewell, E. and Alexander, L. (1990). 'In depth interviewing: researching people'. Longman Cheshire, Melbourne.

Morton, S.R. and Price, P.C. (1994). R \& D for sustainable use and management of Australia's rangelands. In: R \& D for sustainable use and management of Australia's rangelands: Proceedings of a national workshop and associated papers (Eds S.R. Morton and P.C. Price) pp. 3-18. Land and Water Resources Research and Development Corporation, Canberra.

Murdoch, J. and Clark, J. (1994). Sustainable knowledge. Geoforum 25: 115-32.

Northern Territory Pastoral Land Board (1995). Pastoral land board annual report 1994/95. Northern Territory Department of Lands, Planning and Environment, Darwin. 
Northern Territory Pastoral Land Board (1996). Pastoral land board annual report 1995/96. Northern Territory Department of Lands, Planning and Environment, Darwin.

Ortmann, M. (1992). The new pastoral land act - a co-operative approach to pastoral land management. In: NT cattleman's association yearbook 1991/92, pp. 21-30. NT Cattleman's Association, Darwin.

Orum, A.M., Feagin, J.R. and Sjoberg, G. (1991). Introduction: The nature of the case study. In: 'A case for the case study' (Eds A.M. Orum, J.R. Feagin and G. Sjoberg) pp. 1-26. University of North Carolina Press, Chapel Hill.

Patton, M.Q. (1990). 'Qualitative evaluation and research methods'. Sage, Newbury Park.

Pickup, G. (1985). The erosion cell - a geomorphic approach to landscape classification in range assessment. Australian Rangeland Journal 7: 11421.

Pickup, G. (1988). Modelling arid zone soil erosion at the regional scale. In: 'Fluvial geomorphology of Australia' (Ed R. Warner) pp. 105-28. Academic Press, Sydney.

Robinson, J. (1999). 'Bushman of the red heart: Ben Nicker 1908-1941'. Central Queensland University Press, Rockhampton.

Russell, D. and Ison, R. (2000). The research-development relationship in rural communities: An opportunity for contextual science. In: 'Agricultural extension and rural development: Breaking our of traditions (Eds R. Ison and D. Russell) pp. 10-31. Cambridge University Press, Cambridge. 
Shulman, A.D. and Penman, R. (1994). Why study rangeland values? Some practices that scientists have much to answer for. Rangeland Journal 16: 265-72.

Walsh, D. (2002) Centre Land Watch: Monitoring by pastoralists for pastoralists. In: 'Shifting Camp' (Eds S. Nicholson, and D. Wilcox) pp. 360-1. Twelfth Biennial Rangelands Conference Australian Rangelands Society, Kalgoorlie.

Williams, D.M. (2000). Representations of nature on the Mongolian steppe: An investigation of scientific knowledge construction. American Anthropologist 102: 503-19.

Wilson, A.D., Tongway, D.J., Greatz, R.D. and Young, M.D. (1984). Range inventory and monitoring. In: 'Management of Australia's rangelands' (Eds G.N. Harrington, A.D. Wilson and M.D. Young) pp. 113-27. CSIRO, Melbourne. 


\section{Notes}

${ }^{1}$ I am not entirely satisfied with the word 'persistence'. It potentially implies that pastoral environmental knowledge is static. As I attempt to explain, this is not my view. Instead, I am suggesting that while certain structural features of pastoral knowledge are exhibiting persistence, this knowledge is flexible in other respects and able to change without necessarily challenging these structural characteristics. As a corollary, I also observed strong persistence in beliefs such as the ability of the country to renew itself and in the 'gardening' role of cattle alongside considerable changes in management practices. This was particularly evident in one pastoral family that had radically changed its approach to station management in order to gain environmental and economic benefits, yet still retained these persistent characteristics in their thinking about country and cattle. It is such examples that lead me to write that there are complexities in pastoral environmental knowledge and its development that lie beyond my analysis and research to date.

2'Ethnographic' research is an approach that focuses on depth and understanding rather than breadth of coverage. It often aims to investigate the culture of a group of people and to explore that group's norms and values. Culture is difficult to define but can generally refer to the everyday world we inhabit and to the processes by which meaning is generated. For example, this paper employs such a concept of culture by examining dimensions of how relatively inanimate 'land' becomes 'country', known and understood through experience and social norms, including those to do with land use and stewardship. Ethnography commonly employs a range of qualitative methods, including, for example, participant observation, unstructured interviewing and use of multiple sources.

${ }^{3}$ The Inland Review was a short-lived Alice Springs publication. It had close links with the pastoral industry.

${ }^{4}$ In July 1964 the NT Land Board received verbal submissions from pastoralists and others from Alice Springs and surrounding areas. A transcript is held at the Department of Business, Infrastructure and Resource Development library at the Arid Zone Research Institute in Alice Springs, item RO27.

${ }^{5}$ I understand Waudby to be using 'lignified' to refer to grass that has dried up and become 'woody' in that it has lost its suppleness and moisture. This is the only instance of the use of this term by pastoralists that I have come across. A more common term is probably 'rank'.

${ }^{6} \mathrm{I}$ am using this term in the sense of this landscape development having a purposeful and predetermined direction and endpoint. 